\title{
On the Causal Relationship between Household Consumption and Economic Growth in Saudi Arabia
}

\author{
Moayad Al Rasasi (Corresponding author) \\ Economic Research Department, Saudi Central Bank \\ P.O Box 2992, Riyadh 11169, Saudi Arabia
}

Tel: 966-11-463-3000Ｅ-mail: moalrasasi@gmail.com

Yasir Alzahrani

Economic Research Department, Saudi Central Bank

P.O Box 2992, Riyadh 11169, Saudi Arabia

Tel: 966-11-463-3000Ｅ-mail: yialzahrani@sama.gov.sa

Mohammed Alassaf

Economic Research Department, Saudi Central Bank

P.O Box 2992, Riyadh 11169, Saudi Arabia

Tel: 966-11-463-3000_E-mail: moalassaf@ sama.gov.sa

Received: March 9, 2021 Accepted: April 15, $2021 \quad$ Published: April 18, 2021

doi:10.5296/ber.v11i2.18386 URL: https://doi.org/10.5296/ber.v11i2.18386

\begin{abstract}
This research paper explores the causal relationship between household consumption and economic growth over the period of 1980-2017. Hence, it applies the popular cointegration tests alongside the most common causality test. The empirical analysis shows the presence of a positive long run relationship between household consumption and economic growth. In specific, we find evidence revealing that a one percent increase in household expenditures on consumption would boost economic growth by 0.7 percent. Furthermore, causality analysis, based on Granger (1969) test, suggests that variation in household consumptions could explain changes in economic growth.
\end{abstract}


Keywords: consumption, economic growth, causality, cointegration

\section{Introduction}

Assessing the role of consumption expenditures in promoting economic growth has been one of the most important research topics that have received a great deal of attention in macroeconomic research. Hence, there are alternative perspectives regarding the impact of consumption on economic growth depending on various theoretical viewpoints. Broadly speaking, some economists built their analysis based either on the Keynesian consumption theory developed by Keynes (1936) or on the life-cycle hypothesis proposed by Modigliani and Brumberg (1954). This in turn encourages some economists and policy analysts to believe in the essential role of consumption spending in boosting economic growth. Therefore, understanding the nexus between consumption and output growth becomes crucial from policymakers' perspectives, since maintaining sustainable economic growth is the principal concern of macroeconomic policies, and the government requires a steering mechanism for that.

Indeed, there are many studies exploring the relationship between consumption expenditures, either public or household, and economic growth on various advanced and less advanced economies by employing multiple econometric approaches. However, even with this large share of literature, there is a very limited amount of research assessing the role of consumption on economic growth for the case of Saudi Arabia. In other words, the existent consumption-growth literature covering Saudi Arabia tends to analyze the effects of energy consumption on economic growth (e.g. Al-Iriani 2006; Alkhathlan \& Javid 2013; Alshehry \& Belloumi 2015), rather than evaluating the impact of private or public consumption on growth. This in turn motivates us to examine the effects of household consumption expenditures on economic growth.

Understanding how changes in consumption affect economic growth is very crucial for policymakers in Saudi Arabia as multiple policies have been introduced including the introduction of a value-added tax (VAT) and energy price reforms alongside the stimulus package targeting low-income households. Therefore, it is important to comprehend how private consumption evolves over time as it enables policymakers to design and implement the appropriate policies. Additional motivation arises from the actual data published by the General Authority for Statistics of Saudi Arabia revealing that real household consumption represents about 56 percent of the real non-oil sector output in 2000; this percentage increased to 61 percent in 2017. One, then, can easily be aware of the essential role of household consumption in promoting the non-oil economic growth. Some economic indicators in Saudi Arabia support the notion of consumption-led growth. For instance, consumers' loans, cash withdrawals, and point of sales over the last decade are fluctuating and associated with the economic growth of the non-oil sector as Table (1) shows. 
Table 1. Growth Rates for Selected Economic Indicators (percentage)

\begin{tabular}{|l|l|l|l|l|}
\hline Year & Real Non-Oil GDP & Consumer Loans & Cash Withdrawals from ATM & Point of Sales \\
\hline 2000 & $4.2 \%$ & $12.1 \%$ & $16.7 \%$ & $17.4 \%$ \\
\hline 2001 & $3.3 \%$ & $15.3 \%$ & $12.9 \%$ & $38.9 \%$ \\
\hline 2002 & $3.3 \%$ & $16.5 \%$ & $29.8 \%$ & $43.9 \%$ \\
\hline 2003 & $3.6 \%$ & $22.8 \%$ & $-3.5 \%$ & $33.8 \%$ \\
\hline 2004 & $9.3 \%$ & $32.0 \%$ & $16.8 \%$ & $21.6 \%$ \\
\hline 2005 & $7.4 \%$ & $32.2 \%$ & $22.7 \%$ & $17.1 \%$ \\
\hline 2006 & $8.4 \%$ & $9.1 \%$ & $13.5 \%$ & $10.3 \%$ \\
\hline 2007 & $8.9 \%$ & $0.3 \%$ & $10.6 \%$ & $27.3 \%$ \\
\hline 2008 & $8.0 \%$ & $-3.4 \%$ & $22.8 \%$ & $30.4 \%$ \\
\hline 2009 & $5.9 \%$ & $3.8 \%$ & $8.5 \%$ & $9.4 \%$ \\
\hline 2010 & $9.5 \%$ & $9.1 \%$ & $13.9 \%$ & $27.7 \%$ \\
\hline 2011 & $8.2 \%$ & $20.5 \%$ & $23.5 \%$ & $37.6 \%$ \\
\hline 2012 & $5.5 \%$ & $16.4 \%$ & $8.2 \%$ & $23.6 \%$ \\
\hline 2013 & $6.4 \%$ & $9.1 \%$ & $6.8 \%$ & $9.8 \%$ \\
\hline 2014 & $4.9 \%$ & $7.3 \%$ & $9.5 \%$ & $19.2 \%$ \\
\hline 2015 & $3.2 \%$ & $3.1 \%$ & $6.3 \%$ & $8.0 \%$ \\
\hline 2016 & $0.2 \%$ & $3.6 \%$ & $-3.1 \%$ & $5.7 \%$ \\
\hline 2017 & $1.3 \%$ & $0.03 \%$ & $-3.3 \%$ & $9.7 \%$ \\
\hline
\end{tabular}

Source: Saudi Central Bank (SAMA) Database

With this background emphasizing the essential role of consumption in boosting economic growth, the main objective of this paper is to evaluate the impact of household consumption on economic growth in the context of the Saudi Arabian economy. To do so, we utilize real annual data over the period of 1980-2017 and apply the most common econometric procedures to assess such link. To our knowledge, unlike previous empirical research on Saudi Arabia analyzing the nexus between energy consumption and economic growth, this paper examining the effects of overall expenditures of household consumption on goods and services.

The rest of the paper is organized as follows. An overview of empirical studies is presented in section 2, and a description of the dataset is contained in section 3. The applied empirical tests and discussion of the results are covered in section 4, while section 5 summarizes the findings of this paper.

\section{Literature Review}

There is a growing body of literature attempting to analyze the impact of consumption on economic growth with notable attention to advanced and less developed and emerging economies. By reviewing the existing studies on various countries, we have noted that some of these research papers have tended to use different measures for consumption that could be 
either private, public, or consumption per capita. Likewise, some studies have tended to use various measures for economic growth as well as adding new variables contributing to consumption and economic growth such as inflation or government expenditures.

Guisan (2004), for instance, investigated the causal relationship between real economic growth and real consumption in both the US and Mexico by employing annual data for the 1970-2002 period. His study attempted to examine such a relationship by applying various tests consisting of Granger causality, the new version of Granger causality, the cointegration test developed by Engle-Granger, and Hausman tests. The findings of these tests did not give a clear indication of the existence of such relation. For instance, the new "modified" Granger causality test showed the presence of bidirectional causality running from consumption to economic growth and vice versa in both countries. However, the Granger causality test revealed the existence of causality using US data, but it is not valid for the case of Mexico.

Gomez-Zaldivar and Ventosa-Santaularia (2009) examined the link between consumption and economic growth in Mexico and the US by utilizing annual data spanning from 1971 to 2002 and applying standard tests of cointegration and causality. The empirical results showed the lack of both cointegration and causality between the variables under investigation for the case of Mexico; however, the presence of causality and cointegration between consumption and economic growth was confirmed for the case of the US. In particular, the reported evidence indicated that changes in consumption are able to predict changes in economic growth. Chioma (2009) adopted the simple Ordinary Least Square (OLS) estimation method to examine the relationship between economic growth and personal consumption in Nigeria over the period starting from 1994 to 2007. The empirical findings revealed that higher economic growth does not lead to higher personal consumption.

To assess the essential role of private consumption in promoting economic growth, Mishra (2011) conducted an analysis using annual observations covering the period 1950-2009 for the Indian economy. The most common econometric procedures such as Johansen and Juselius (1990) cointegration and Granger (1969) causality tests were implemented. The results of these tests indicated the presence of valid cointegration relationship between private consumption and economic growth. Likewise, the long run causal relationship running from consumption to economic growth was confirmed; however, the short run causality between the two variables is absent. Moreover, Bin-Amin (2011) adopted the most popular cointegration tests developed by Johansen and Juselius (1990) as well as the ARDL cointegration approach initiated by Persaran \& Shin (1995) in order to study the long run relationship between consumption and GDP growth in Bangladesh. To reach such an objective, he relied on annual data from 1976 to 2009 to conduct these tests that validate the presence of a long run relationship between consumption and economic growth. Furthermore, the result of a Granger (1960) causality test confirmed that there is a causality running from economic growth to consumption, but not vice versa.

By relying on Bulgarian and Russian data to assess the existence of a long run relationship between consumption and economic growth, Genchev (2012) used consumption per capita and GDP per capita with annual data over the 1990-2010 period. The tests of cointegration 
indicated that there was a long and significant relationship between per capita consumption and per capita GDP in both countries, suggesting the essential role income plays in promoting consumption. Ramli and Andriani (2013) investigated the effects of consumption, investment, and government expenditures on Indonesian economic growth for the period starting from 2001 to 2010. The analysis of this study was based on a simple regression being estimated by the Ordinary Least Square (OLS) estimation method. The empirical results showed the influential role of these variables in influencing economic growth; in specific, the resulting evidence suggests that an increase in consumption of one percent increases economic growth by 0.67 percent. On the other hand, Bala (2014) attempted to explore the relationship between household consumption and economic growth in Romania over the period of 1990-2012. The Engle and Granger (1987) cointegration test revealed the absence of a long run relationship between these variables.

Nguyen (2015) attempted to probe if there is a long relationship between consumption and economic growth in Bangladesh by analyzing annual data from 1980 to 2014. The author concluded that there is a bidirectional Granger causality between real consumption and real GDP, implying both variables are mutually affecting each other. Kim (2017) used a factor analysis approach to evaluate the relationship between consumption and economic growth in 52 Asian countries from the period of 2012 to 2016. The paper used 18 variables including, among other variables, GDP per capita reflecting economic growth, consumer spending, savings, and government spending. The empirical evidence confirmed the existence of a positive relationship between consumer spending and economic growth in Asia. In addition to the mentioned studies, Tapsin and Hepsage (2014) provided a comprehensive literature review on the link between economic growth and consumption.

Concerning the literature focusing on Saudi Arabia, we have found that the prevailing research is analyzing the specific relationship between energy consumption and economic growth, rather than considering the overall consumption of goods and services. The findings of these studies (e.g. Al-Iriani 2006; Alkhathlan \& Javid 2013; Alkhathlan et al. 2012; Alshehry \& Belloumi 2015; Algahtani et al. 2017) seem to be mixed depending on the variables and econometric techniques that are used in the analysis. None of the observed literature, based on our knowledge, examines the nexus of household consumption and economic growth in Saudi Arabia. Henceforth, this research paper aims to enrich the literature by investigating such a relationship.

\section{Data}

The purpose of this paper is to investigate the dynamics of the relationship between household consumption and economic growth in Saudi Arabia. To this end, this study utilizes two economic variables: the real non-oil Gross Domestic Product (GDP) measuring economic growth, and real private final consumption expenditure (C) as a measure for household consumption. This study relies on annual observations expressed in natural logarithm form for the sample period from 1980 to 2017. The data series used are obtained from the General Authority for Statistics (GASTAT) of Saudi Arabia. The non-oil GDP deflator measure was used in order to convert consumption from nominal to real terms over 
the period 1980-2000 since real consumption data are not available for this period.

\section{Empirical Method and Results}

\subsection{Testing for Unit Root}

An evaluation of the stochastic properties of macroeconomic time series has become necessary in empirical analysis in order to avoid spurious relationships. Prompted by this necessity, eminent economists have developed various unit root tests evaluating the time series properties of macroeconomic and financial time series. In this paper, therefore, we follow the empirical literature by checking the stochastic properties of the utilized macroeconomic variables. Thus, we apply the unit root tests originated by Kwiatkowski et al. (1992) since it is more efficient and can overcome the issues with earlier unit root tests. That is to say, unit root tests such as Dickey \& Fuller (1979) and Phillips \& Perron (1988) seem to be weak in power as noted by Schwert (1987). The results obtained from this test are summarized in table (2) and confirm that all variables are integrated of order one.

Table 2. Kwiatkowski et al. (1992) Unit Root Test

\begin{tabular}{|l|l|l|l|l|}
\hline & \multicolumn{2}{l|}{ KPSS Test } \\
\hline & \multicolumn{2}{|l|}{ Level Data } & \multicolumn{2}{l|}{ First Difference } \\
\hline & Constant & Trend & Constant & Trend \\
\hline C & 0.66 & 0.20 & 0.13 & 0.12 \\
\hline Non-oil GDP & 0.69 & 0.19 & 0.31 & 0.10 \\
\hline
\end{tabular}

Note: The KPSS 5\% critical values for constant $=0.463$, and for trend $=0.146$.

\subsection{Testing for Cointegration Relationship}

The results obtained from unit root tests, as presented in table (2), confirm that the two macroeconomic variables under investigation, real non-oil GDP and consumption, are integrated of order one. This finding in turn might indicate the presence of a cointegrating relationship between the two variables as suggested by Engle and Granger (1987). To assess whether a cointegration relationship exists or does not; this paper relies on the most popular cointegration tests, namely Trace and Maximum Eigenvalue tests developed by Johansen and Juselius (1990). The results of both tests, as shown in table (3), suggest the presence of a cointegration relationship between real non-oil GDP and real private final consumption expenditure at the 5 percent significance level. The presence of such a cointegration relationship indicates that all these variables seem to share the same trend, which in turn suggests that the cointegration relationship is not spurious and that it is valid for analysis and forecast. 
Table 3. Johansen and Juselius (1990) Cointegration Tests

\begin{tabular}{|c|c|c|c|}
\hline Null Hypothesis & Alternative Hypothesis & Test Statistics & 5\% Critical Value \\
\hline Panel A: Trace Test \\
\hline$r=0$ & $r=1$ & 19.67 & 15.49 \\
\hline$r \leq 1$ & $r=2$ & 1.42 & 3.84 \\
\hline \multicolumn{3}{|l|}{ Panel B: Maximum Eigenvalue Test } \\
\hline$r=0$ & $r=1$ & 18.25 & 14.26 \\
\hline$r \leq 1$ & $r=2$ & 1.42 & 3.84 \\
\hline
\end{tabular}

Note: $r$ denotes the number of cointegration vectors.

\subsection{Interpreting Long Run Relationship}

With the existence of a long run relationship, as confirmed by cointegration tests of Johansen and Juselius (1990), it is essential to interpret this relationship to comprehend how changes in household consumption may affect the growth rate of the non-oil sector in Saudi Arabia. To do so, we estimate the following long run relationship, as given by equation (1), based on the Ordinary Least Squares (OLS) estimation method.

$$
G D P_{t}=\beta_{0}+\beta_{1} C_{t}+\beta_{2} \text { Trend }+\varepsilon_{t}
$$

where $G D P_{t}, C_{t}$, Trend, and $\varepsilon_{t}$ represent the real non-oil GDP at time t, household consumption at time $\mathrm{t}$, the time trend, and the error term at time $\mathrm{t}$ respectively. Likewise, $\beta_{0}$ denotes the constant term while $\beta_{1}$ is the coefficient reflecting the impact of household consumption on economic growth. The time trend coefficient $\left(\beta_{2}\right)$ captures all other factors affecting economic growth other than household consumption.

The estimated results of the empirical model, as summarized in table (4), reveal the significant impact of household consumption on economic growth in the long-run. Put differently, when household consumption inches up by one percent, the growth of the non-oil GDP would be expected to increase by 0.7 percent. This suggests that the essential role consumption plays on the growth performance of the Saudi economy, a non-surprising result given the fact that consumption is a key engine driving the growth in Saudi Arabia and it accounts about 61 percent of the non-oil GDP in 2017 and about 58.5 percent over the last decade on average. In addition, in order to assess the fitness of the model, we rely on the $\mathrm{R}^{2}$ statistics that quantifies the variations in real economic growth that is due to household consumption. In other words, $\mathrm{R}^{2}$ indicates 97 percent of the economic growth variations are explained by its explanatory variables (household consumption and time trend). 
Table 4. Parameter Estimates of Long Run Relationship

\begin{tabular}{|c|c|c|c|c|}
\hline & $\beta_{0}$ & $\beta_{1}$ & $\beta_{2}$ & $\mathrm{R}^{2}$ \\
\hline Parameter estimates & $7.56 *$ & $0.69 *$ & 0.02 & \multirow[t]{2}{*}{0.97} \\
\hline t-values & $(12.16)$ & $(22.38)$ & $(5.14)$ & \\
\hline
\end{tabular}

\subsection{Error Correction Model}

In the previous sub-section, we analyzed the long-run relationship between household consumption and economic growth; however, it is crucial to assess the dynamic of this relationship when it moves away from its long run path to its short run path. To do so, we estimate the following error correction model (ECM), as given by specification (2).

$$
\Delta G D P_{t}=\delta_{0}+\sum_{i=1}^{S} \delta_{1 i} \Delta G D P_{t-i}+\sum_{i=1}^{S} \delta_{2 i} \Delta C_{t-i}+\lambda E C M_{t-1}+\varepsilon_{t}
$$

where $\Delta G D P_{t}, \Delta C_{t}$, and $\varepsilon_{t}$ represent the change in real non-oil GDP at time t, the change in household consumption at time $\mathrm{t}$, and the error term at time t, respectively. $\delta_{0}, \delta_{1 i}, \delta_{2 i}$, and $\lambda$ are the estimated parameters reflecting the impacts of the variables inserted in specified model (2). We rely on the Akaike criteria (AIC) to choose the suitable lag length. To this end, it is vital to emphasize that $E C M_{t-1}$ signifies the error correction term at time $t-1$ and calculated from model (1) as shown in specification (3).

$$
E C M_{t}=G D P_{t}-\beta_{0}-\beta_{1} C_{t}-\beta_{2} \text { Trend }
$$

The estimated parameters of the error correction model as shown in specification (2) are presented in table (5), bearing in mind that the optimal lag length based on AIC criteria is two.

Table 5. Parameter Estimates of ECM

\begin{tabular}{|l|c|c|c|c|c|}
\hline & $\delta_{11}$ & $\delta_{12}$ & $\delta_{2}$ & $\delta_{22}$ & $\lambda$ \\
\hline Parameter estimates & $0.73 *$ & 0.10 & 0.02 & $-0.11 *$ & $-0.09 * *$ \\
\hline t-values & 3.85 & 0.60 & 0.33 & -2.22 & -1.81 \\
\hline
\end{tabular}

$(*),(* *)$ denote $5 \%$ and $10 \%$ significance level respectively.

From the estimated coefficients, we note that the impact of household consumption in the short-run seem to be positive though it is insignificant after one lag; however, it becomes significant with negative impact after two lags. The estimated coefficient $(\lambda)$ would enable us to gauge the period for which economic growth return to its equilibrium condition after having moved away from its steady state condition. Strictly speaking, $\lambda$ has the expected sign, which is negative and significant at 10 percent level, implying that economic growth responds to this disequilibrium between these two variables. In other words, the speed of adjustment to equilibrium path is slow, and it takes roughly 10 years to return to its steady 
state. This finding also supports the finding of a cointegration relationship. Additionally, it highlights the essential role of consumption in capturing the variation in economic growth, a role that can be verified by applying a causality test such as that of Granger (1969), as follows.

\subsection{Testing for Causality}

The presence of a cointegration relationship among the variables under the scope of this paper encourages us to investigate if there is a causal effect running from household consumption to real non-oil GDP and vice versa. To address this issue, the most common causality test, Granger (1969), is used. In simple words, this test depends on the past values of household consumption in predicting the current changes in real non-oil GDP growth, given its past values. The same approach is applied when we test for causality running from non-oil real GDP to consumption.

That is to say, it is possible to assess whether changes in household consumption can predict changes in economic growth or vice-versa. To conduct this test, the vector error correction model (VCEM) is the suitable model to evaluate whether the changes in consumption could predict changes in real non-oil GDP growth since the variables are cointegrated as confirmed from the Johansen and Juselius (1990) tests. To that end, the following bivariate VCE model, as outlined by equations (4) and (5), are estimated by the MLE method.

$$
\begin{gathered}
\Delta G D P_{t}=\delta_{0}+\sum_{i=1}^{s} \delta_{1 i} \Delta G D P_{t-i}+\sum_{i=1}^{s} \delta_{2 i} \Delta C_{t-i}+\lambda_{1} E C M_{t-1}+\epsilon_{1 t} \\
\Delta C_{t}=\varphi_{0}+\sum_{i=1}^{s} \varphi_{1 i} \Delta G D P_{t-i}+\sum_{i=1}^{s} \varphi_{2 i} \Delta C_{t-i}+\lambda_{2} E C M_{t-1}+\epsilon_{2 t}
\end{gathered}
$$

where $\Delta G D P_{t}$, and $\Delta C_{t}$ are the change in real non-oil GDP at time $\mathrm{t}$, and the change in household consumption at time $\mathrm{t}$ respectively, while $\epsilon_{1 t}$ and $\epsilon_{2 t}$ are the error terms associated with specification (4) and (5) at time t respectively. The constant coefficients are $\delta_{0}$ and $\varphi_{0}$, while $\delta_{1 i}, \delta_{2 i}, \varphi_{1 i}$, and $\varphi_{2 i}$ are the parameters associated with the lagged economic growth and household consumption. The estimated coefficients $\lambda_{1}$ and $\lambda_{2}$ represent the deviation of the dependent variables from the long run equilibrium. The Akaike criteria (AIC) was applied to determine the appropriate lag length $(s)$.

To evaluate the causal relationship between the variable under investigation, we test the following hypothesis. The first null hypothesis is that changes in household consumption do not granger cause changes in economic growth, which implies testing $\delta_{1 i}=\delta_{2 i}=0$. In the same manner, the second hypothesis states that changes in economic growth do not cause changes in household consumption, in other words, testing whether $\varphi_{1 i}=\varphi_{2 i}=0$ holds or not.

The results of Granger causality test are summarized in table (6) and they indicate that there is causality running from consumption to real non-oil GDP at 10 percent significant level. This in turn indicates that changes in household consumption are able to predict changes in economic growth, while changes in real non-oil GDP are not able to capture changes in household consumption. 
Table 6. Results of Granger Causality Test based on VEC Model

\begin{tabular}{|l|c|l|l|}
\hline Null Hypothesis & $\chi^{2}$ & P-value & Decision \\
\hline$\Delta G D P \nrightarrow \Delta$ Consumption & 2.74 & 0.254 & Fail to reject the Null Hypothesis \\
\hline$\Delta$ Consumption $\nrightarrow \Delta G D P$ & 5.83 & 0.054 & Reject the Null Hypothesis \\
\hline
\end{tabular}

It is crucial to shed light behind the rationale regarding the causality running from economic growth to household consumption and vice versa. In Saudi Arabia, citizens tend to prefer working for the public sector due to its job security; it is evident by the public sector wage bill, representing around 45.2 percent of total government expenditures and around 58.2 percent of the total current expenditures in 2017 (note 1). It is also important to note that the public wage bill increases during periods when the economy is preforming well as the government sector tends to increase hiring. This increase in employment leads, in turn to an increase in household consumption resulting from the increase in disposable income. The same relation holds for the private sector as well given the reliance of the private sector on government spending. Not only that, but given the welfare nature of Saudi Arabia, in which a segment of Saudi society receives some form of financial assistance (e.g. elderly people, widows, divorced women, orphans, college and university students, unemployed people, and poor people) from the government which has the effect of increasing household consumption and aggregate demand.

\section{Conclusion}

The primary goal of this research paper is to examine the impact of household consumption on economic growth on the one hand, and to evaluate whether variations in household consumption produce changes in economic growth on the other hand. To reach this end, various econometric techniques are implemented. The empirical findings indicate the existence of the causal relationship between the two variables. In addition, the cointegration relationship is confirmed, and it shows that increases of household consumption by one percent tend to be associated with growth rate of 0.7 percent of the real non-oil GDP over the long run.

These empirical results show the importance of consumption in promoting economic growth in Saudi Arabia. This in turn encourages policymakers to bear this in mind in designing and implementing suitable macroeconomic policies that ensure the sustainability of economic growth. In other words, the implemented fiscal policies (e.g. VAT, and energy price reforms) tend to rationalize consumption behaviour in general and to mitigate the waste that could be observed from energy consumption in particular. This in turn may lead to lower consumption over time, as people tend to rationalize their spending, which might affect economic growth in adverse manner.

Therefore, to maintain a sustainable level of consumption, alternative policies such as the Citizen's Account and higher living cost allowances were also implemented with the objective of sustaining equitable economic growth via mitigating the possible impacts on household consumption. Likewise, it is essential to note that as one of the primary objectives 
of vision 2030 is to enable Saudi women to participate efficiently in the economy, which in turn implies the major role of women participation in the labour market. The increase of female labour participation, in particular in various economic sectors would result in increase in both disposal income and consumption, which would boost economic growth. Furthermore, policymakers need to consider that the launch of Financial Sector Development Program opens new channels for savings and investments to which consumers allocate portion of their income, a previously unavailable outlet that could change the dynamics between consumption and economic growth in Saudi Arabia.

For further research, it is possible to analyze the link of household consumption with other macroeconomic variables such as inflation, wages, savings, or investment. Likewise, it would be important to model the consumption function in Saudi Arabia in order to highlight the key factors determining consumption in Saudi Arabia. Equally important for further research is the effect of the National Transformation Program, specifically savings initiatives, on smoothing consumption over time throughout the business cycle, as well as the role of the National Transformation Program, and different programs under Vision 2030 on creating a suitable economic environment that contribute to the absorption of economic shocks.

\section{References}

Algahtani, G. J., Alharbi, S. S., \& Alqahtani, A. M. (2017). Revisiting the Nexus between Economic Growth and Energy Consumption. SAMA Working Paper, No.17/02.

Al-Iriani, M. A. (2006). Energy-GDP Relationship Revisited: An Example from GCC Countries Using Panel Causality. Energy Policy, 34(17), 3342-3350.

https://doi.org/10.1016/j.enpol.2005.07.005

Alkhathlan, K., \& Javid, M. (2013). Energy Consumption, Carbon Emissions and Economic Growth in Saudi Arabia: An Aggregate and Disaggregate Analysis. Energy Policy, 62(C), 1525-1532. https://doi.org/10.1016/j.enpol.2013.07.068

Alkhathlan K., Alam M., \& Javid M. (2012). Carbon Dioxide Emissions, Energy Consumption and Economic Growth in Saudi Arabia: A Multivariate Cointegration Analysis. British Journal of Economics, Management and Trade, 2(4), 327-39.

https://doi.org/10.9734/BJEMT/2012/1673

Alshehry, A. S., \& Belloumi, M. (2015). Energy Consumption, Carbon Dioxide Emissions and Economic Growth: The Case of Saudi Arabia. Renewable and Sustainable Energy Reviews, 41, 237-247. https://doi.org/10.1016/j.rser.2014.08.004

Bălă, R. M. (2014). Exploring the Long-Run Relationship between GDP and Private Consumption of Romania through Cointegration Analysis. Ovidius University Annals, Economic Sciences Series, O(1), 257-262.

Bin-Amin, S. (2011). Causal Relationship between Consumption Expenditure and Economic Growth in Bangladesh. World Journal of Social Sciences, 1(2), 158-169.

Chioma, N. J. (2009). Causal Relationship between Gross Domestic Product and Personal 
Consumption Expenditure of Nigeria. African Journal of Mathematics and Computer Science Research, 2(8), 179-183.

Dickey, D., \& Fuller, W. (1979). Distribution of the estimators for autoregressive time series with a unit root. Journal of the American Statistical Association, 74(366), 427-431. https://doi.org/10.1080/01621459.1979.10482531

Elliott, G., Rothenberg, T. J., \& Stock, J. H. (1996). Efficient tests for an autoregressive unit root. Econometrica, 64(4), 813-836. https://doi.org/10.2307/2171846

Engle, R. F., \& Granger, C. W. J. (1987). Co-integration and error correction: Representation, estimation, and testing. Econometrica, 55(2), 251-276. https://doi.org/10.2307/1913236

Genchev, Evgeni. (2012) Analysis of Income-Consumption Relationship in Bulgaria and Russia. журнал «Молодой ученый», 4(39), 115-119.

Guisan, M. C. (2004). A Comparison of Causality Tests Applied To the Bilateral Relationship between Consumption and GDP in the USA and Mexico. International Journal of Applied Econometrics and Quantitative Studies, 1(1), 115-130.

Gomez-Zaldivar, M., \& Ventosa- Santaularia, D. (2009). The Bilateral Relationship between Consumption and GDP in Mexico and the U.S.: A Comment. Applied Econometrics and International Development, 9(1), 78-90.

Granger, C. W. J. (1969). Investigating the causal relations by econometric models and cross-spectral methods. Econometrica, 37(3), 424438. https://doi.org/10.2307/1912791

Johansen, S., \& Juselius, K. (1990). Maximum likelihood estimated and inference on cointegration with application to the demand for money. Oxford Bulletin of Economics and Statistics, 52(2), 169-210. https://doi.org/10.1111/j.1468-0084.1990.mp52002003.x

Keynes, J. M. (1936). The General Theory of Employment, Interest and Money. Published by Harcourt, Brace and Company, and prented in the U.S.A. by the Polygraphic Company of America, New York.

Kim, H. (2017). The Effect of Consumption on Economic Growth in Asia. Journal of Global Economics, 5(3), 1-8. https://doi.org/10.4172/2375-4389.1000259

Kwiatkowski, D., Phillips, P. C. B., Schmidt, P., \& Shin, Y. (1992). Testing the null hypothesis of stationarity against the alternative of a unit root. Journal of Econometrics, 54(1-3), 159-178. https://doi.org/10.1016/0304-4076(92)90104-Y

Mishra, P. K. (2011). Dynamics of the Relationship between Real Consumption Expenditure and Economic Growth in India. Indian Journal of Economics \& Business, 10(4), 541-551.

Modigliani, F., \& Brumberg, R. H. (1954). Utility analysis and the consumption function: an interpretation of cross-section data. In K. K. Kurihara, (Ed.), Post-Keynesian Economics (pp. 388-436). New Brunswick, NJ. Rutgers University Press.

Nguyen, C. V. (2015). Dynamics between Bangladeshi Real Consumption and Economic 


\section{Macrothink}

Business and Economic Research

ISSN 2162-4860 2021, Vol. 11, No. 2

Growth. Daffodil International University Journal of Business and Economics, 9(2), 1-9.

Pesaran, M., \& Shin, Y. (2001). An autoregressive distributed lag modeling approach to cointegration analysis. In S. Storm, A. Holly \& P. Diamond (Eds.), Centennial Volume of Ranger Frisch. Cambridge University Press, Cambridge.

Phillips, P. C. B., \& Perron, P. (1988). Testing for unit roots in time series regression. Biometrika, 75(2), 335-346. https://doi.org/10.1093/biomet/75.2.335

Ramli, A., \& Andriani, A. A. (2013). The Effects of Consumption, Private Investment, and Government Expenditures on Economic Growth in South Sulawesi, Indonesia. Journal of Economics and Sustainable Development, 4(14), 145-153.

Schwert, G. W. (1987). Effects of model specification on tests for unit roots in macroeconomic data. Journal of Monetary Economics, 20(1), 73-103.

https://doi.org/10.1016/0304-3932(87)90059-6

Tapsin, G., \& Hepsag, A. (2014). An Analysis of Household Consumption Expenditures in EA-18, European Scientific Journal, 10(16), 1-12.

\section{Notes}

Note 1. Source: Budget Performance Reports for 2017 published by the Ministry of Finance of Saudi Arabia.

\section{Copyright Disclaimer}

Copyright for this article is retained by the author(s), with first publication rights granted to the journal.

This is an open-access article distributed under the terms and conditions of the Creative Commons Attribution license (http://creativecommons.org/licenses/by/4.0/). 